\title{
CONTROLE E COERÇÃO: A PEDAGOGIA DO OLHAR NA ESPACIALIDADE DO TEATRO E DAS ORGANIZAÇÕES
}

\section{RESUMO}

Este ensaio aborda o tema da coerção e do controle, amplamente tratado no campo dos estudos críticos em Administração, privilegiando o espaço físico. Porém o faz numa perspectiva alternativa: toma a evolução histórica da espacialidade teatral e estabelece analogias com a espacialidade nas organizações. Para tanto, são analisados o anfiteatro grego, o teatro de Roma, os palcos medievais, o palco italiano e, adicionalmente, a sala de cinema. O objetivo é argumentar que no espaço físico controla-se, pedagogicamente, o olhar do indivíduo para que propósitos políticos, econômicos e culturais sejam realizados. Tal acontece tanto pelo emprego de modos coercitivos e diretos de controle quanto de modos normativos, mais sutis.

\section{Sylvia Constant Vergara}

FGV-EBAPE

José Luis Felício dos Santos de Carvalho

Faculdades Ibmec

\section{Ana Paula Cortat Zambrotti Gomes}

FGV-EBAPE

\footnotetext{
ABSTRACT This essay approaches the themes of coercion and control, extensively treated in the field of critical management studies, putting emphasis on the physical environment. However it is done in an alternative route: it takes the historical evolution of the physical space of the theater as a source for analogies in order to analyze the physical environment of work. The Greek amphitheater, the theater from Rome, the Middle Ages' stage and the Italian stage are analyzed. An additional phase analyzed is the movie theater. The objective is to argue that in the physical space the individual's look is controlled in a pedagogy way in order to achieve political, economic and cultural purposes. It happens by using either direct and coercive methods of control as well as more subtle normative methods.
}

PALAVRAS-CHAVE Estudos Críticos em Administração, controle e coerção, espacialidade, pedagogia do olhar. KEY WORDS Critical management studies, control and coercion, physical environment, pedagogy of the look. 


\section{INTRODUÇÃo}

A literatura sobre poder, controle, dominação e coerção vem, nos últimos anos, sendo beneficiada com um crescente número de estudos e pesquisas, sobretudo depois dos consagrados estudos de autores como Max Weber, Amitai Etzioni e Michel Foucault. Pesquisas sobre a eficácia da utilização dos espaços físicos como mecanismo de controle e coerção mencionam tanto formas diretas quanto as que buscam interferir na subjetividade dos indivíduos (Alcapadini e Almeida, 2002; Vergara e Gomes, 2002). Nesses estudos, a espacialidade é analisada em relação aos mecanismos pelos quais os corpos dos indivíduos são tornados dóceis, aprisionados e vigiados (Foucault, 1987) pelos agentes de controle organizacional.

Este ensaio propõe uma perspectiva alternativa de investigação sobre o tema. Parte-se da premissa de que uma forma relevante de dominação exercida pelo sistema produtivo com relação à força de trabalho diz respeito ao controle do olhar do indivíduo, exercido por intermédio da espacialidade. Já que a relação do corpo humano com o espaço ocorre por meio da apreensão de imagens e de seu processamento, o controle do corpo dos indivíduos passa, então, pelo controle de seu olhar. Afirmamos ser esse controle de natureza pedagógica. Entende-se por pedagogia um processo por meio do qual as gerações mais novas vão incorporando os usos e costumes, práticas e hábitos, idéias e crenças das que as antecederam. Ela é exercida por pessoas especializadas, em lugares adequados (Larroyo, 1970). Os indivíduos são "educados" para ver o que determinados propósitos religiosos, políticos, econômicos e culturais desejam que eles vejam.

A pedagogia do olhar faz parte de um projeto milenar de dominação dos espaços naturais, cuja origem remonta à Antigüidade clássica (Kosovski, 1992). Pode-se observar a evolução dessa pedagogia na história da construção dos edifícios teatrais, assim como na espacialidade física das organizações. O objetivo deste ensaio é estabelecer analogias entre essas duas formas de espacialidade.

Da mesma forma que o exemplo, a ilustração e a metáfora, a analogia pode ser entendida como um método de se construir uma argumentação (Perelman e Olbrechts-Tyteca, 1996). Ela confronta similaridades de estruturas, e tal confrontação segue uma fórmula genérica que pode ser representada pelo enunciado: "A está para B assim como C está para D" (Perelman e Olbrechts-Tyteca, 1996). Ao utilizar uma analogia, tem- se como objetivo confrontar um tema (conjunto dos termos A e B, sobre os quais repousa uma conclusão) com um foro (conjunto dos termos $\mathrm{C}$ e $\mathrm{D}$, que servem para fundamentar o raciocínio). A elaboração de uma analogia não implica que haja uma relação prévia entre os termos de foro e tema; exige-se, em geral, que tema e foro pertençam a diferentes áreas do saber. É assim que o cinema, o jazz e os orixás, por exemplo, têm sido utilizados como analogias para a compreensão de diversos aspectos da vida organizacional (Wood Jr., 2001; Weick, 2002; Vergara e Irigaray, 2000).

O texto está organizado da seguinte forma: primeiro discute-se a questão da espacialidade organizacional e a questão da espacialidade teatral; em seguida, são estabelecidas analogias entre a espacialidade de cinco momentos evolutivos do edifício teatral no Ocidente, com os espaços organizacionais; por fim, são apresentadas as principais conclusões do estudo.

\section{ORGANIZAÇÕES E ESPACIALIDADE}

A relevância acadêmica da presente investigação crítica está em ressaltar os mecanismos pelos quais os edifícios contribuem para estabelecer e reforçar as instâncias ideológicas, políticas e socioeconômicas de dominação (Dale e Burrell, 2002). Estruturas físicas circunscrevem ações e interações de indivíduos ao instalá-los em espaços que têm como objetivos: prover um contexto por meio do qual as pessoas criam um senso de realidade; condicionar as possibilidades para os papéis sociais; organizar as pessoas e suas atividades (Turner, 1999). Deve-se atentar, portanto, para a dimensão política desses espaços, que envolve questões tais como a lógica de repartição do poder, o local de tomada de decisões, a regulação do espaço e sua influência no comportamento humano, a ritualização na criação de cenários nos quais ocorrem a explicitação de papéis sociais. Quando os indivíduos encenam tais papéis, estão sendo tomadas decisões a respeito de "quem ocupará um território, quem poderá mudar para onde e com que freqüência, e quem poderá transitar pelo espaço" (Turner, 1999, p. 261).

A estruturação das organizações depende, portanto, dos aparatos sociopolíticos referentes à espacialidade (Cappelle e Brito, 2002; MacKey, 2002) e que permitem a incorporação de práticas, hábitos e crenças. Assim, tendem a reforçar os mecanismos de alienação, submissão e apatia (Enriquez, 1997). Denunciar o espaço organizacional como mecanismo de con- 
trole e dominação dos indivíduos implica denunciar o controle de seu olhar para atender interesses de desempenho e lucratividade. A eficácia desse controle é pedagógica. A literatura parece ter, no entanto, negligenciado a questão da "educação" do olhar.

Se a interação do indivíduo com o espaço organizacional ocorre por meio da representação de papéis, parece oportuno discutir a teatralidade embutida na divisão e na ocupação do espaço nos contextos organizacionais, a partir dos conceitos dramatúrgicos analisados originalmente por Goffman (1959). Torna-se fundamental compreender como os encenadores do espetáculo propiciado pelo ambiente físico da organização conduzem o olhar de seus atores (e de suas platéias) nesse teatro, de modo a dirigir e controlar o corpo e a mente deles.

Antes de prosseguir, porém, é importante mencionar que não se busca, neste ensaio, fazer uma analogia de cunho cronológico entre a evolução do espaço teatral e o desenvolvimento do espaço nas organizações. A intenção é construir um argumento, no sentido dado a esse termo por Perelman e Olbrechts-Tyteca (1996), sobre o controle do olhar do espectador-indivíduo.

\section{TEATRO E ESPACIALIDADE}

Estudar a concepção e a evolução do edifício teatral no Ocidente significa empreender uma jornada de contemplação de um projeto histórico de controle e dominação do espaço cênico e do olhar dos espectadores (Kosovski, 1992; Rosenfeld, 1993).

Desde os primeiros festins dionisíacos, realizados em clareiras na floresta para os cultos orgiásticos ao deus do indomável, até as modernas sessões de cinema, apresentadas em salas nas quais se pode controlar luz, som e temperatura, as mudanças no locus teatral refletem a transformação de dois aspectos da relação entre o homem e a representação cênica de seu mundo: modificações no próprio espaço e modificações na condução do olhar do espectador, que evolui de uma comunhão pessoal e espontânea da platéia com a imensidão do universo circundante para um foco padronizado em uma fatia determinada da realidade, cuidadosamente escolhida e representada (Mantovani, 1993; Wilson, 2000).

Neste ensaio, essas duas facetas - o desenho do espaço e o olhar do espectador - são discutidas à luz dos contextos históricos que produziram a arte teatral ocidental e que servem como analogias para a com- preensão dessas facetas no ambiente das organizações. A análise do desenho espacial do teatro é feita por meio da observação de duas questões: a ruptura gradual entre os elementos do real, que a encenação passa a incluir dentro do lugar destinado à representação, e os elementos que devem ficar no mundo "lá fora"; e a relação entre as formas retilíneas do palco, representações da ordem e da razão, e as linhas curvas, manifestações do caos e do mito (Barthes, 1990; Kosovski, 1992). Já o tema do olhar do espectador diz respeito à maneira como os encenadores passaram a direcionar a atenção da platéia cada vez mais da natureza para o palco, para os atores, para detalhes cênicos e, com o advento do cinema, para dimensões hiperreais da cena (Betton, 1987; Costa, 1989; Gassner, 1997; Kosovski, 1992).

Inicialmente, examina-se a formação do anfiteatro grego. Em seguida, a apropriação do espaço trágico pelos romanos. Em terceiro lugar, discorre-se acerca dos mistérios medievais. A Renascença traz o quarto modelo espacial, o palco italiano. Finalmente, transfere-se o foco para as modernas salas de cinema. Com cada um desses espaços cênicos são estabelecidas analogias que dizem respeito aos espaços organizacionais.

\section{O ANFITEATRO GREG0: PALCO DOS EMBATES ENTRE DIONISO E APOLO}

As primeiras manifestações cênicas do mundo ocidental - século V a.C. - foram os rituais religiosos chamados ditirambos, representações do mundo mítico praticadas em honra a Dioniso. As orgias dionisíacas aconteciam em círculos abertos em clareiras nas florestas; predominavam o instinto, a magia, o erotismo, o canto e a celebração da vida.

A inserção do primeiro elemento de ordenação ocorreu quando Téspis, o primeiro ator conhecido, construiu uma plataforma retangular, elevou-se acima dos demais brincantes e passou a conduzir a cerimônia com uma máscara de bode (Costa e Remédios, 1988; Kosovski, 1992). Com Téspis, teve-se uma primeira caracterização de um palco; a encenação passou, então, a aprofundar a cisão entre real e imaginário, entre razão e misticismo, e a evolução do espaço teatral caminhou em direção aos anfiteatros fixos. A orquestra, local em que ficava o coro - conjunto de atores que representavam a voz e a consciência do povo - era circular. Para os espectadores, havia bancadas normalmente encostadas ao flanco de uma colina e que formavam um auditório semicircular denominado 
theatron, ou "lugar de onde se vê" (Barthes, 1990; Rosenfeld, 2000).

A cena era composta pelo conjunto de skênê e proskenion. A primeira era um edifício retangular, vertical e permanente, cuja parede frontal servia de cenário. O proskenion era uma plataforma estreita, onde se desenvolvia parte da ação e que, aos poucos, foi se tornando o principal lugar cênico (Mantovani, 1993). A arquitetura do teatro grego desenvolveu-se a partir da representação de uma tensão transformadora entre forças dicotômicas, tais como religião e razão, natureza e cultura, despedaçamento e forma, Dioniso e Apolo, phisis e logos (Kosovski, 1992; Nuñez, 1994). Com os anfiteatros, encontrou-se um certo equilíbrio entre essas forças. Em relação ao desenho espacial, enquanto na orquestra e no theatron predominavam as linhas circulares, na skênê e no proskenion predominavam as retas (Costa e Remédios, 1988). No que tange ao olhar do espectador, ao mesmo tempo em que a cena se apresentava diante de seus olhos, ele também dispunha da possibilidade de contemplar a natureza, o céu e mesmo outras pessoas no theatron.

As primeiras formas de trabalho também testemunharam uma grande autonomia do corpo e do olhar humanos. Dos caçadores e pescadores aos primeiros artesãos, artífices, tecelões e agricultores, os indivíduos eram livres para se integrar ao ambiente da forma que melhor lhes conviesse. O dono de um pedaço de chão poderia arar a terra, plantar um pomar ou deixar que germinasse a paisagem. Quem fazia potes poderia arrumar sua olaria de acordo com seu próprio gosto. O indivíduo era, portanto, livre para decidir como e quanto produzir.

\section{O TEATRO DE ROMA: PÃO, CIRCO E ORDEM}

$\mathrm{Na}$ Grécia, as forças do indomável, representadas pelo círculo da orquestra, onde se dispunha o coro, tinham a mesma importância e destaque de que gozavam as forças do controle, materializadas nas linhas retas da skênê e do proskenion (Barthes, 1990). Na evolução do teatro grego para o romano, entretanto, a representação da voz do povo (coro) foi mitigada e a orquestra perdeu uma de suas metades, que foi substituída por uma linha reta, formando-se um semicírculo. Em seguida, o espaço da orquestra desapareceu, e as linhas retas da skênê e do proskenion passaram a dominar a cena (Mantovani, 1993). A skênê ganhou um volume considerável, chegando a se constituir como um edifí- cio de vários andares em alguns teatros, e o proskenion, com sua área igualmente aumentada, tornou-se uma enorme plataforma em toda a frente do cenário (Bentley, 1981; Gassner, 1997; Rosenfeld, 2000).

Quando os encenadores romanos transformam o aberto anfiteatro grego em um espaço fechado, completando o semicírculo do theatron com outro semicírculo que se fechava atrás da skênê, o olhar do público já não podia vagar pela paisagem natural e se voltava ainda mais para dentro da cena. O passo seguinte, indicado pelo teatro sacro durante a Idade Média, e completado com o palco italiano, seria fechar o teto do teatro, impedindo até mesmo a visualização do céu pela platéia e desvinculando, definitivamente, o espaço cênico da natureza (Gassner, 1997).

\section{A disciplina do espaço organizacional}

No mundo do trabalho, quando o progresso técnico e a divisão do trabalho levaram à emergência do conceito de troca (Fourastié, 1962), o interesse das empresas nascentes voltou-se para a maximização dos retornos obtidos por sua atividade principal. Foram estabelecidas as fundações do capitalismo produtivo (Suret-Canale, 2000).

A divisão do trabalho exige a constituição de mecanismos de controle, dentre os quais a manipulação do espaço. Em nome da eficiência, a racionalidade começa a ser privilegiada e as manifestações do caos passam a ser combatidas. Surgem os patrões e os empregados, os chefes e os comandados; criam-se horários de trabalho; estabelecem-se cronogramas de produção; esboçam-se organogramas. As forças da ordem passam a ditar também a construção do ambiente físico: enquanto o olhar dos patrões se centraliza na perseguição do excedente (Polanyi, 2000), os olhos dos indivíduos devem ser contidos no espaço que produz o excedente, de modo que nada possa interferir no processo de sua apropriação.

Assim como no teatro, também nas organizações criase uma nova realidade dentro do edifício da fábrica, um mundo de corpos curvados ante a necessidade de aumentar a produção. Nesse pequeno mundo começam a se manifestar fortemente a territorialidade e a competição por espaços de sobrevivência (Staub e Bulgacov, 2000) que, por sua vez, estimulam o aparecimento da agressividade e da violência, fazendo da empresa uma arena na qual indivíduos e grupos tentam obter posições de domínio, em função de seus interesses.

As partes mais fracas, oprimidas pela ordem, são, então, enclausuradas no espaço para que o controle 
sobre elas seja exercido de modo mais próximo, objetivo e direto. As janelas para o exterior são fechadas, impedindo o indivíduo de conduzir livremente seu olhar para o mundo. O princípio da clausura, contudo, não é constante nem indispensável. A disciplina trabalha o espaço de maneira flexível e fina (Foucault, 1987). Ainda assim, os olhos dos que trabalham só podem ver aquilo que o chefe deseja; sua imaginação passa a ser igualmente vigiada, controlada e direcionada. Os olhares fixam-se em linhas retas: linhas de montagem, linhas de produção, caixas empilhadas de produtos, pilhas de papel sobre as mesas.

O espaço organizacional transforma-se, então, em espaço disciplinar: "Cada indivíduo no seu lugar; e em cada lugar um indivíduo" (Foucault, 1987, p. 123). Segundo o relato de um trabalhador colhido por Zuboff (1988, p. 139): "Tínhamos o hábito de ver uns aos outros e conversar. Mas agora, com o novo sistema, colocaram divisórias entre nós, pois não devemos ver uns aos outros". Os propósitos pedagógicos do uso dos espaços físicos são confirmados por um gestor:

Nada justifica as pessoas interagirem entre si. O sistema permite que exista uma privacidade entre você e o sistema. Com a mobília que escolhemos, há um reforço da mensagem: 'você está aqui para fazer o seu trabalho'. A mobília deve aumentar a produtividade, pois coloca cada indivíduo em seu próprio cubículo. (Zuboff, 1988, p.139).

\section{OS MISTÉRIOS MEDIEVAIS E OS PALCOS SANTOS}

Em virtude do fortalecimento da Igreja Católica como instituição, houve uma ascensão do cristianismo como força política hegemônica na passagem da Antiguidade clássica para a Idade Média, o que trouxe conseqüências significativas para o espaço cênico. A cena medieval traduzia a necessidade de conduzir o olhar do espectador em uma direção que acompanhasse convenções e normas predeterminadas pelo clero (Kosovski, 1992; Magaldi, 1991; Mantovani, 1993).

No século V, a Igreja deu início à eliminação do edifício teatral especializado. Muitos teatros legados por gregos e romanos foram fechados, destruídos ou adaptados para abrigar verdadeiras cidadelas. Em um segundo momento, a Igreja percebeu a força do teatro e passou a persegui-lo como instituição; proibiu-se o teatro pagão, e o teatro oficial confundiu-se com a re- presentação do sagrado e com a própria Igreja. O imaginário popular deveria centrar-se na Bíblia, e o melhor lugar para sua manifestação cênica seria o próprio edifício religioso (Gassner, 1997). A dramaturgia sacra começava com a consagração das missas e, aos poucos, deslocava-se da nave central das igrejas para os espaços laterais intercolunas, em que se montaram as primeiras "mansões", pequenos cenários que formavam quadros da Bíblia (Bentley, 1981; Kosovski, 1992; Magaldi, 1991; Nuñez, 1994).

Em um dos extremos do edifício da Igreja situavase o inferno, e no pólo oposto, perto da nave central, o paraíso. Entre eles, dispunham-se diversas cenas nas "mansões", locais em que as etapas da trajetória entre inferno e céu eram detalhadas para o público, que se deslocava de uma "mansão" a outra (Kosovski, 1992; Mantovani, 1993). Esse espaço das "mansões" era configurado por uma arquitetura pesada, escura e soturna, uma vez que a técnica de construção de janelas que dessem acesso ao exterior eram ainda incipiente. Nesse tipo de arquitetura, os espectadores eram oprimidos por meio de uma privação do contato com o mundo externo e por uma condução, não só de seu olhar, mas também de seu corpo como um todo (Kosovski, 1992).

\section{A invasão do espaço do trabalho}

Em relação às organizações, os primeiros métodos de vigilância e controle dos indivíduos, desenvolvidos em instituições tais como prisões e casernas, tinham como função tornar dóceis seu corpo. Assim como os espectadores do teatro medieval eram conduzidos de uma "mansão" a outra, os indivíduos nos escritórios têm seu trânsito regulado e seu olhar educado para detectar a presença de seus chefes. O olhar direto dos indivíduos volta-se para a execução de suas tarefas, enquanto seu olhar periférico se funde aos próprios sistemas de vigilância: "Onde está o capataz? Para onde foi meu colega? Se ele foi ao banheiro, por que está demorando tanto?"

A estrutura predominante nas fases nascentes da industrialização capitalista tinha raízes tanto militares quanto monásticas e objetivava subjugar o tempo e o espaço dos indivíduos à disciplina imposta externamente, ligada ao tempo e ao espaço do patrão. Na Inglaterra dos séculos XVII e XVIII, as workhouses - clausuras que transformavam indigentes, mulheres e crianças em operários com cargas de trabalho de 18 horas diárias (SuretCanale, 2000) - eram controladas pelas mesmas paróquias que celebravam os santos mistérios. 
Nas fábricas e nos escritórios também se impôs uma relação de opressão análoga, o que remete à perspectiva foucaultiana segundo a qual o corpo é peça central para a análise das organizações (Burrell, 1998). Essa perspectiva sugere como as organizações empregam práticas disciplinares para criar conhecimento e poder, fixando os indivíduos em espaços conceituais e geográficos (Townley, 2001). O olhar e o corpo dos indivíduos sofrem proibições e obrigações, conforme relata Segnini (1992, p. 107) a respeito de uma organização brasileira:

A mesa, a cadeira, o caixa, constituem as células nas quais os indivíduos são alocados e expostos à vigilância, possibilitando sempre determinar onde estão, o que estão fazendo, assim como avaliar a quantidade e a qualidade do serviço realizado.

Por outro lado, a estética do espaço é utilizada para que os indivíduos passem a amar sua própria servidão (Dale e Burrell, 2002). Os ambientes são planejados com espaços livres, móveis ergonômicos, equipamentos modernos, cafeteria e até espaços privados - salas de reunião, cabines telefônicas e armários (Alcadipani e Almeida, 2002). O olhar do indivíduo se encanta com os ambientes modernos.

Pelo fato de as igrejas ocuparem posição central nas cidades, e por conta de as encenações exigirem cada vez mais espaço físico e mais tempo na liturgia, gradativamente o teatro saiu do edifício da igreja, primeiro para suas escadarias e depois para a própria cidade, para suas ruas e prédios. Apareceram na realização cênica cada vez mais referências ao cotidiano e o religioso foi apropriado pelo profano. Analogamente, as regras do mundo do trabalho espraiam-se por toda a sociedade e confundem-se com as relações familiares, religiosas e de lazer.

\section{A CAIXA MÁGICA DO PALCO ITALIANO}

No final da Era Medieval, por volta do século XV, o teatro iniciou um processo de ruptura entre a cena e a religião. Peças profanas começaram a ser apresentadas em carroças transformadas em palcos que os próprios atores conduziam de aldeia em aldeia, estacionando-as nas praças dos mercados (Bentley, 1981; Gassner, 1997; Mantovani, 1993). Os estalajadeiros passaram a oferecer o espaço de seus pátios internos para o estacionamento da carroça-palco, e algumas estalagens tornaram-se teatros permanentes.

O destino do teatro passou, aos poucos, a ser regido pelas condições socioeconômicas das comunidades que adentravam a Renascença (Roubine, 1982). A concepção do espetáculo à italiana e do palco desenvolvido para abrigá-lo obedeceu à satisfação dos dois principais públicos interessados: a aristocracia e a burguesia (Bentley, 1981; Gassner, 1997; Nuñez, 1994; Wilson, 2000). A estrutura da sala italiana era "o espelho de uma hierarquia social" (Roubine, 1982, p. 75), e, de acordo com esta, não se podia esperar que o pequeno comerciante desfrutasse das mesmas facilidades que os duques e barões. A ocupação dos camarotes centrais, balcões, frisas laterais e galerias mostrava a posição social de cada espectador. O dispositivo italiano repetia o mundo "lá fora". Não existia mais relação alguma do espaço com as forças do caos, do divino e do indômito; a ordem reinava suprema (Kosovski, 1992; Rosenfeld, 1993).

O dispositivo teatral italiano típico consistia em uma sala fechada, no formato de um cubo ou de volume retangular, ao fundo da qual havia um tablado igualmente retangular, que ficava, portanto, emoldurado pelas duas paredes laterais e pelo fundo do edifício (Aumont, 1993; Gassner, 1997; Mantovani, 1993; Wilson, 2000). A platéia tinha uma relação quase sempre frontal com a cena, intermediada somente pela "quarta parede", um conceito que se refere à frente do palco como uma "parede transparente para o público e opaca para o ator" (Kosovski, 1992, p. 107). Impunha-se ao público uma relação fundamentalmente passiva com o espetáculo, na medida em que a platéia não podia intervir na cena, devendo manter-se sentada no mesmo lugar do início ao fim da representação. O olhar do espectador era conduzido para o palco por meio do próprio desenho do edifício, de linhas predominantemente retas, geometricamente calculadas (Kosovski, 1992).

O surgimento da luz elétrica, no final do século XIX, ensejou duas conseqüências importantes para a cena à italiana (Aumont, 1993). Primeiro, o palco se iluminava e a platéia ficava às escuras, canalizando para a encenação toda a atenção do público; abria-se uma janela perfeitamente retangular, iluminada, diante dos espectadores, que tinham sua postura contemplativa sublinhada. Segundo, o rápido desenvolvimento da iluminação cenográfica permitiu que algumas áreas específicas do palco ganhassem ainda mais destaque, caracterizando um movimento nítido e significativo na pedagogia do olhar imposta ao público pela evolução do teatro ocidental. 


\section{0 espaço hierárquico do trabalho}

Como no palco italiano, a atribuição do espaço nas organizações se efetua, dentre outros princípios, segundo o sistema hierárquico (Fischer, 1993); há uma nítida correlação entre a importância do cargo, o tamanho do espaço e a personalização do local de trabalho. O lugar maior ou menor que se ocupa indica a posição mais ou menos elevada na organização; o acesso a janelas tem como único determinante o status ou a posição hierárquica do ocupante daquele ambiente (Robbins, 2000); a personalização do espaço indica a margem de liberdade e poder detidos por um indivíduo (Konar et al., 1982).

Nos palcos teatrais, o desenvolvimento da iluminação cenográfica consolidou o controle do olhar do espectador. Analogamente, nas organizações, as "luzes" se acendem para a produção, canalizando a atenção do indivíduo para os resultados organizacionais. Aos mecanismos de controle já utilizados para aprisionar a subjetividade do indivíduo, um outro é incorporado: o tecnológico. Assim, os sistemas eletrônicos de gestão passam a regular as comunicações, por meio de linhas telefônicas individuais; as entradas e as saídas na empresa, por meio de pontos eletrônicos; e a permanência, por meio de circuitos fechados de televisão (Cappelle e Brito, 2002). Atuam, ainda, sobre o olhar do indivíduo, só permitindo o acesso aos sites da Internet e às mensagens de correio eletrônico autorizados pela empresa. As organizações transformam-se em superpanópticos ou panópticos virtuais (Cappelle e Brito, 2002; Zuboff, 1988). É a chamada transição de uma lógica das sociedades disciplinares para a lógica das sociedades de controle (Deleuze, 1992). Se as primeiras, representadas pelo panóptico, funcionavam por confinamento físico contingente, as segundas funcionam por controle contínuo e comunicação instantânea.

\section{O CINEMA CONQUISTA AS FRONTEIRAS DA ILUSÃO PICTÓRICA}

Com a ascensão da burguesia e as transformações tecnológicas impostas pelo capitalismo de mercado e pela sociedade industrial, as investigações empreendidas pela arte caminharam à procura de novos domínios plásticos (Kosovski, 1992). O teatro à italiana e a busca da estética ilusionista que procurava reproduzir a realidade na encenação haviam preparado os espectadores para a chegada do cinema, no final do século XIX e início do século XX (Knight, 1970). Em contraste com a máquina ilusionista em que se transfor- mara a arquitetura teatral, a agilidade cinematográfica revolucionou a arte cênica, a qual se voltou para atingir um mimetismo pictórico da realidade (Betton, 1987; Kosovski, 1992). Pediu-se aos espectadores que se tornassem ainda mais passivos e contemplativos.

A conquista definitiva da verossimilhança com a realidade foi obtida com o auxílio precioso do espaço cênico. Diante dos espectadores, exibe-se uma tela branca retangular que parece pairar no ar, suspensa apenas por seu brilho quase sólido. A sala de exibição permanece totalmente apagada e os estímulos visuais e auditivos são tão poderosos a ponto de impedir qualquer atitude que não seja a entrega à encenação (Betton, 1987; Kosovski, 1992). Recursos de câmera conduzem a atenção do espectador para imagens panorâmicas de proporções gigantescas e para detalhes microscópicos da cena. E os chamados efeitos especiais conseguem criar realidades críveis a partir de elementos fictícios.

\section{A virtualização do espaço organizacional}

Em relação às organizações, no contexto atual de grandes transformações econômicas, políticas e sociais muitas delas igualmente ilusórias e fictícias -, elas passam a sofrer as pressões de um novo ambiente de negócios. Para adequar-se ao novo espetáculo pós-industrial, as organizações implodem e explodem, originando novas formas de divisão e coordenação do trabalho e de relacionamento com o ambiente (Wood Jr., 2001). Aqui, o corpo ainda não deixou de ser peça central, nem o controle de ser explícito.

O que parece estar em operação, porém, é a transformação dos elementos de controle ou condução dos indivíduos: "A sociedade pós-moderna é uma produção cinemática e dramatúrgica” (Pelzer, 2002, p. 37). Nesse novo ambiente de negócios, o corpo está sendo, aos poucos, esquecido ou amortecido como no cinema, e o foco passa a ser a mente, num contexto de controle cultural, caracterizado por forças internas como vocabulário padrão, compartilhamento da história organizacional, senso de pertencer à organização e compreender o seu papel nela (Steil e Sanches, 1998). A cultura organizacional aparece como forte elemento de um controle disfarçado, baseado no discurso da participação e do comprometimento (Steil e Barcia, 1999; Wood Jr., 2001).

A abertura do espaço, característica dos open-offices contemporâneos, pode parecer um retorno ao teatro grego, às sociedades pré-capitalistas, quando o espectador-indivíduo tinha a autonomia do olhar e da produção. Porém, esses espaços contemporâneos consti- 
tuem mais um mecanismo de controle, capazes de atender à necessidade de dominação inerente à organização do trabalho (Alcapadini e Almeida, 2002; Fischer, 1993). Os defensores das novas tecnologias parecem crer que o sofrimento no trabalho foi por elas bastante atenuado (Faria, 2002). Entretanto, elas escondem formas de sofrimento diferentes daquelas que caracterizavam os processos produtivos anteriores. O elemento preponderante nessa nova estruturação diz respeito à variável psicológica, contribuindo para o aumento dos processos de tolerância subjetiva.

Efeitos especiais, que no cinema criam realidades críveis, produzem nas organizações indivíduos conformados com as regras a que são submetidos. Controles normativos anestesiam a mente, de modo que os indivíduos passem a ser agentes do seu próprio controle. Entram em ação as metas, a remuneração variável, o trabalho em equipe e o controle pelos pares, e a empregabilidade. Técnicas de gerenciamento de impressões difundem-se (Carvalho e Grisci, 2002; Mendonça, Vieira e Espírito Santo, 1999).

\section{CONCLUSÃO}

Nos 25 séculos transcorridos desde as primeiras manifestações teatrais gregas até os cinemas atuais, a civilização ocidental parece ter conseguido utilizar o espaço para impor aos espectadores uma pedagogia do olhar, tal como se observa nas organizações. Se no anfiteatro grego os espectadores tinham autonomia para olhar a cena ou a paisagem, nas organizações havia, igualmente, autonomia do olhar e do corpo. O indivíduo era livre para produzir e integrar-se ao ambiente. Já o teatro romano caracterizava-se pelo fechamento do espaço; nele, o olhar do espectador foi direcionado para o palco. Analogamente, nas organizações, o indivíduo perdeu a liberdade para decidir como e quanto produzir. Seu olhar foi conduzido para as linhas de montagem, para os papéis sobre as mesas. Nos palcos santos, não só o olhar do espectador foi conduzido, mas, também, seu corpo. Nas organizações, consolidou-se o poder disciplinar (Burrell, 1998; Foucault, 1987). No palco italiano, a pedagogia do olhar do espectador foi potencializada pelos recursos de iluminação cenográfica. Nas organizações, a pedagogia do olhar do indivíduo foi potencializada pela tecnologia. Surgiram os "superpanópticos" ou "panópticos virtuais". Finalmente, com a chegada do cinema, os corpos foram "amortecidos". O olhar do espectador foi domi- nado para que as mentes pudessem estar aptas a assimilar padrões extremos de ilusionismo. Nas organizações, técnicas de gerenciamento de impressões anestesiam as mentes dos indivíduos.

Embora o fenômeno teatral não possa ser restrito somente ao edifício e ao palco, talvez a percepção de controle e coerção seja mais visível exatamente nesses espaços, uma vez que a relação do homem com seu ambiente físico foi ponto determinante para que as sociedades humanas pudessem chegar ao estágio atual de seu desenvolvimento. Em um mundo no qual o espetáculo dita as normas de organização, produção e consumo, a espacialidade ganha contornos nítidos na manipulação do ambiente de trabalho. A eficácia da pedagogia do olhar do indivíduo é garantida pelo emprego de modos coercitivos e diretos de controle e também daqueles normativos ou disfarçados, que ampliam as possibilidades de dominação. Ao controlar o olhar dos indivíduos, as organizações podem reduzir suas possibilidades de auto-expressão, constranger sua criatividade, limitar sua liberdade e estimular a passividade (Meisiek, 2002).

Encerramos o presente ensaio com uma sugestão de futuras investigações a partir da perspectiva aqui defendida. Trata-se de tentar compreender de que forma se expressa o controle do olhar do indivíduo na denominada "sociedade do conhecimento", na qual a sustentabilidade de uma vantagem competitiva depende da prestação de serviços. Se as empresas dependem de operadores de serviços para elaborar uma oferta de valor, e se esses operadores muitas vezes se encontram fisicamente distantes da empresa - assim como um consultor em visita de auditoria empresarial ou mesmo um técnico enviado a uma residência para consertar um computador -, como se estabelece a pedagogia do olhar? Nesse sentido, talvez a idéia dos reality shows, nos quais existe um "grande irmão" onipresente, possa trazer contribuições interessantes.

\section{REFERÊNCIAS BIBLIOGRÁFICAS}

ALCADIPANI, R.; ALMEIDA, A. Por fora bela viola, por dentro... análise crítica sobre a gestão do espaço nas organizações através de um estudo de caso sobre a implementação de um escritório aberto no Brasil. Revista Interdisciplinar de Marketing, v. 1, n. 1, 2002. (http://www.rimar-online.org).

AUMONT, J. A imagem. São Paulo: Papirus, 1993.

BARTHES, R. O óbvio e o obtuso: ensaios sobre fotografia, cinema, pintura, teatro e música. Rio de Janeiro: Nova Fronteira, 1990. 
BENTLEY, E. A experiência viva do teatro. Rio de Janeiro: Zahar, 1981.

BETTON, G. Estética do cinema. São Paulo: Martins Fontes, 1987.

BURRELL, G. Ciência normal, paradigmas, metáforas, discursos e genealogia da análise. In: CALDAS, M.; FACHIN, R.; FISCHER, T. Handbook de estudos organizacionais. São Paulo: Atlas, 1998.

CAPPELLE, M. C. A.; BRITO, M. J. Relações de poder no espaço organizacional: o caráter disciplinar das práticas de gestão de pessoas em uma organização de desenvolvimento de software. In: ENCONTRO NACIONAL DA ASSOCIAÇÃO NACIONAL DOS PROGRAMAS DE PÓS-GRADUAÇÃO EM ADMINISTRAÇÃO, 26., 2002, Salvador. Anais... Salvador: Anpad, 2002.

CARVALHO, M. L.; GRISCI, C. L. I. Gerenciamento de impressão em entrevista de seleção: camaleões em cena. In: ENCONTRO NACIONAL DA ASSOCIAÇÃO NACIONAL DOS PROGRAMAS DE PÓS-GRADUAÇÃO EM ADMINISTRAÇÃO, 26., 2002, Salvador. Anais... Salvador: Anpad, 2002

COSTA, A. Compreender o cinema. 2. ed. São Paulo: Globo, 1989.

COSTA, L. M.; REMÉDIOS, M. L. R. A tragédia: estrutura e história. São Paulo: Ática, 1988.

DALE, K.; BURRELL, G. An-aesthetics and architecture, Tamara-Journal of Critical Postmodern Organization Science, v. 2, n. 1, 2002.

DELEUZE, G. Conversações. São Paulo: Editora 34, 1992.

ENRIQUEZ, E. A organização em análise. Petrópolis: Vozes, 1997.

FARIA, J. H. Economia política do poder: uma proposta teórico-metodológica para o estudo e a análise das organizações. In: ENCONTRO NACIONAL DE ESTUDOS ORGANIZACIONAIS, 2., 2002, Recife. Anais... Recife: Anpad, 2002.

FISCHER, G. N. Espaço, identidade e organização. In: CHANLAT, J. F. O indivíduo na organização: dimensões esquecidas. São Paulo: Atlas, 1993.

FOUCAULT, M. Vigiar e punir. Petrópolis: Vozes, 1987.

FOURASTIÉ, J. Por que trabalhamos? São Paulo: Difusão Européia do Livro, 1962.

GASSNER, J. Mestres do teatro I. 3. ed. São Paulo: Perspectiva, 1997.

GOFFMAN, E. The presentation of self in everyday life. New York: Anchor Books, 1959

KNIGHT, A. Uma história panorâmica do cinema: a mais viva das artes. Rio de Janeiro: Lidador, 1970.

KONAR, E.; SUNDSTROM, E.; BRADY, C.; MANDEL, D.; RICE, R. Status demarcation in the office. Environment and Behavior, v. 14, n. 5, p. 561580, 1982 .
KOSOVSKI, L. Teatro e encenação: um olhar sobre o palco. 1992. Dissertação (Mestrado) - Escola de Comunicação da UFRJ, Rio de Janeiro, 1992.

LARROYO, F. História geral da pedagogia. São Paulo: Mestre Jou, 1970.

MACKEY, S. Drama, landscape and memory: to be is to be in place. Research in Drama Education, v. 7, n. 1, 2002.

MAGALDI, S. Iniciação ao teatro. São Paulo: Ática, 1991.

MANTOVANI, A. Cenografia. 2. ed. São Paulo: Ática, 1993.

MEISIEK, S. Post-event effects theatrical events in organizations. Organization as theatre and organizational theatre: from metaphor to intervention - Academy of Management Symposium on Theatrics, Washington, August 2002.

MENDONÇA, J. R. C.; VIEIRA, M. M. F; ESPÍRITO SANTO, T. M. V. Gerenciamento de impressões, comunicações e ações simbólicas como elementos facilitadores na gestão de processos de mudança organizacional. In: ENCONTRO NACIONAL DA ASSOCIAÇÃO NACIONAL DOS PROGRAMAS DE PÓS-GRADUAÇÃO EM ADMINISTRAÇÃO, 23., 1999, Foz do Iguaçu. Anais... Foz do Iguaçu: Anpad, 1999.

NUÑEZ, C. F. P. O teatro através da história. Rio de Janeiro: Centro Cultural Banco do Brasil/Entourage Produções Artísticas, 1994.

PELZER, P. 'Dead Man': um encontro com o passado desconhecido. Revista de Administração de Empresas, v. 42, n. 4, 2002.

PERELMAN, C.; OLBRECHTS-TYTECA, L. Tratado da argumentação - a nova retórica. São Paulo: Martins Fontes, 1996.

POLANYI, K. A grande transformação: As origens da nossa época. 2. ed. Rio de Janeiro: Campus, 2000.

ROBBINS, S. P. Organizational behavior. 9. ed. Upper Saddle River: PrenticeHall, 2000.

ROSENFELD, A. O teatro épico. 4. ed. São Paulo: Perspectiva, 2000.

ROSENFELD, A. Prismas do teatro. São Paulo: Perspectiva/Edusp, 1993.

ROUBINE, J. J. A linguagem da encenação teatral. Rio de Janeiro: Zahar, 1982.

SEGNINI, L. R. P. Sobre a identidade do poder nas relações de trabalho. In: FLEURY, M. T. L.; FISCHER, R. M. (Org.). Cultura e poder nas organizações. São Paulo: Atlas, 1992.

STAUB, I. D.; BULGACOV, S. Territorialidade, competição e papéis gerenciais: um estudo de agências bancárias de Curitiba. In: ENCONTRO NACIONAL DA ASSOCIAÇÃO NACIONAL DOS PROGRAMAS DE PÓSGRADUAÇÃO EM ADMINISTRAÇÃO, 24., 2000, Florianópolis. Anais.. Florianópolis: Anpad, 2000. 
STEIL, A. V.; BARCIA, R. M. Aspectos estruturais das organizações virtuais. In: ENCONTRO NACIONAL DA ASSOCIAČ̃̃O NACIONAL DOS PROGRAMAS DE PÓS-GRADUAÇÃO EM ADMINISTRAÇÃO, 23., 1999, Foz do Iguaçú. Anais... Foz do Iguaçu: ANPAD, 1999.

STEIL, A. V.; SANCHES, E. N. Comprometimento organizacional como uma estratégia de controle. In: ENCONTRO NACIONAL DA ASSOCIAÇÃO NACIONAL DOS PROGRAMAS DE PÓS-GRADUAÇÃO EM ADMINISTRAÇÃO, 22., 1998, Foz do Iguaçu. Anais... Foz do Iguaçu: Anpad, 1998.

SURET-CANALE, J. As origens do capitalismo (séculos XV a XIX). In: PERRAULT G. O livro negro do capitalismo, 3. ed. Rio de Janeiro: Record, 2000.

TOWNLEY, B. Conhecimento e poder nas organizações. In: DAVEL, E.; VERGARA, S. C. (Org.). Gestão com pessoas e subjetividade. São Paulo: Atlas, 2001.
TURNER, J. H. Teorização analítica. In: GIDDENS, A.; TURNER, J. H. Teoria social hoje. São Paulo: Unesp, 1999.

VERGARA, S. C.; GOMES, A. P. C. Z. Escritórios abertos: interação ou controle? In: ENCONTRO NACIONAL DA ASSOCIAÇÃO NACIONAL DOS PROGRAMAS DE PÓS-GRADUAÇÃO EM ADMINISTRAÇÃO, 26., 2002, Salvador. Anais... Salvador: Anpad, 2002.

VERGARA, S. C.; IRIGARAY, H. A. R. Os orixás da administração. Revista de Administração Pública, v. 34, n. 2, 2000.

WEICK, K. A estética da imperfeição em orquestras e organizações. Revista de Administração de Empresas, v. 42, n. 3, 2002.

WILSON, E. The theater experience. 8. ed. New York: McGraw-Hill, 2000.

WOOD JR, T. Organizações espetaculares. Rio de Janeiro: FGV, 2001.

ZUBOFF, S. In the age of the smart machine. New York: Basic Books, 1988

Artigo recebido em 28.10.2002. Aprovado em 28.11.2003.

\section{Sylvia Constant Vergara}

Professora Titular da FGV-EBAPE. Doutora em Educação pela UFRJ. Mestre em Administração Pública pela FGV-EBAPE. Interesses de pesquisa em metodologia de pesquisa, comportamento organizacional, desenvolvimento gerencial, gestão da educação corporativa.

E-mail: vergara@fgv.br

Endereço: FGV - Praia de Botafogo, 190 - sala 533 - Rio de Janeiro - RJ, 22250-900.

\section{José Luis Felício dos Santos de Carvalho}

Professor das Faculdades Ibmec. Doutor em Administração pelo IAG/PUC-Rio. Interesses de pesquisa em teoria de organizações, comportamento organizacional, marketing, ensino e pesquisa em administração.

E-mail: zkcarvalho@hotmail.com

Endereço: Avenida Rui Barbosa, 560/101 - Flamengo - Rio de Janeiro - RJ, 22250-020.

\section{Ana Paula Cortat Zambrotti Gomes}

Mestre em Administração Pública pela FGV-EBAPE. Interesses de pesquisa em metodologia de pesquisa, espacialidade nas organizações.

E-mail: apaula@fgv.br

Endereço: FGV - Praia de Botafogo, 190 - sala 533 - Rio de Janeiro - RJ, 22250-900. 